\title{
Penerapan K-Means Clustering untuk Klasifikasi Serangan Cyber pada Syslog File
}

\author{
I Wayan Ardiyasa \\ Institut Teknologi dan Bisnis STIKOM Bali \\ e-mail: ardi@stikom-bali.ac.id \\ Diajukan: 11 Mei 2020; Direvisi: 29 Juni 2020; Diterima: 10 Juli 2020
}

\begin{abstract}
Abstrak
Cybercrime adalah aktivitas kejahatan yang menggunakan teknologi komputer sebagai sarana bertujuan untuk mendapatkan akses informasi dan data yang bersifat privasi sehingga menimbulkan kerugian. Kejahatan penggunaan teknologi informasi meningkat seiring tingginya pengguna teknologi dikarenakan akses informasi saat ini yang sangat mudah dan tidak pedulinya pengguna terhadap keamanan data maupun sistem bagi pihak penyedia maupun pengelola. Selain itu semakin mudahnya akses informasi pada suatu website yang terhubung dengan jaringan internet yang mengakibatkan meningkatnya kejahatan komputer seperti web defacing. Syslog merupakan sebuah protokol untuk system logging dan mencatat aktivitas pengguna dengan format file text pada suatu perangkat seperti perangkat komputer server. Permasalahan muncul ketika file syslog memiliki ribuan catatan aktivitas serangan, sehingga sangat sulit untuk mendapatkan informasi serangan secara cepat. Untuk itu diperlukan clustering untuk mengelompokkan jenis serangan pada syslog file. Jenis serangan yang dilakukan clustering yaitu SQL Injection, XSS Attack dan LFI Attack. Kebaruan dari penelitian ini adalah klasifikasi serangan cyber pada file syslog.log dengan menggunakan metode K-Means Clustering Untuk clustering serangan cyber pada file syslog.log dan pembobotan menggunakan metode TF-IDF untuk mendapatkan data numerik. Penelitian ini menghasilkan aplikasi analisis serangan cyber pada file syslog.log berbasis web untuk membantu pihak investigator digital forensic di dalam analisis dan mendapatkan informasi serangan cyber.
\end{abstract}

Kata kunci: K-Means Clustering, Cyber, Syslog, Digital forensic.

\begin{abstract}
Cybercrime is a criminal activity that uses computer technology as a means intended to gain access to information and data that constitutes privacy that causes harm. The crime of using information technology is increasing With the increase in technology users accessing information today which is very easy and does not care about the user's data or system security for providers as well as providers. In addition, easy access to information on web sites that are connected to the internet network related to computer problems such as web defacing. Syslog is a protocol for logging systems and records user activity in a text file format on a device such as a computer server device. The problem arises with compiling the syslog file to have a lot of records of attack activity, it is very difficult to get attack information quickly. This requires a cluster to classify types of attacks on the syslog file. Types of attacks carried out are SQL Injection, XSS Attack and LFI Attack. The novelty of this research is the collection of cyberattacks on the syslog.log file using the K-Means Clustering method for clustering cyberattacks on the syslog.log file and weighting using the TF-IDF method to obtain numerical data. This research makes a cyberattack analysis application in the web-based syslog.log file to help digital investigators in forensic analysis and obtain cyberattack information.
\end{abstract}

Keywords: K-Means Clustering, Cyber, Syslog, Digital forensic.

\section{Pendahuluan}

Teknologi sebagai perangkat yang dikembangkan untuk membantu pekerjaan manusia di dalam kehidupannya sehari-hari. Dengan penggunaan teknologi tepat guna seperti teknologi informasi dan komunikasi masyarakat sangat terbantu untuk melakukan komunikasi dan mencari informasi dengan mudah dan cepat. Semakin pesat perkembangan teknologi informasi dan komunikasi pengguna menjadi terbantu di dalam mengelola dan mengolah informasi yang bisa diakses secara luas karena seluruh komponen perangkat keras dan perangkat lunak terhubung menjadi satu ke dalam jaringan internet atau 
publik. Informasi yang berada pada suatu website, baik informasi yang terdapat pada halaman interface maupun administrator tidak secara otomatis dijamin aman dikarenakan adanya risiko terdapatnya celah pada lapisan keamanan yang memungkinkan disalahgunakan oleh pihak yang tidak berwewenang [1].

Ada informasi yang sifatnya terbuka dan ada pula informasi yang bersifat private. Namun, di satu sisi sistem yang menyimpan informasi tersebut banyak yang memiliki vulnerability, namun banyak juga sistem yang memiliki tingkat keamanan yang tinggi. Dengan adanya kelemahan pada sistem, akan mengakibatkan adanya peluang bagi attacker untuk melakukan tindakan cybercrime maka diperlukan sistem pengamanan baik dari sisi aplikasi maupun komputer server.

Server merupakan perangkat utama dalam sebuah sistem komunikasi jaringan yang berfungsi sebagai penyedia layanan atau service dalam sebuah jaringan. Sebagai penyedia layanan, service sistem yang berjalan pada server harus mampu berjalan secara real-time. Di dalam monitoring service running pada komputer server diperlukan pencatatan dalam bentuk log service secara real-time untuk mencatat aktivitas service yang berjalan pada server. Log service adalah catatan atau riwayat akses ke sebuah sistem service yang dijalankan oleh sebuah server [2]. Syslog adalah standar untuk meneruskan pesan log di jaringan IP. Istilah untuk Syslog sering digunakan untuk protokol Syslog yang sebenarnya, serta aplikasi atau pustaka yang mengirim pesan Syslog [3]. Komputer server yang terhubung ke dalam jaringan publik sangat rentan terhadap serangan cyber, apabila itu terjadi maka diperlukan langkah investigasi untuk mendapatkan informasi sumber serangan pada file syslog.log. Aplikasi berbasis web dengan menggunakan metode K-means Clustering untuk mengelompokkan jenis serangan pada file syslog.log dan menggunakan metode TF-IDF untuk konversi data serangan menjadi data numeric. Kebaruan dari penelitian ini adalah klasifikasi serangan cyber pada file syslog.log secara komputerisasi menggunakan metode K-Means Clustering, sehingga mampu mengelompokkan jenis serangan sesuai dengan jenis serangan yang ada dan menghasilkan suatu informasi serangan cyber. Tujuan dari penelitian ini adalah untuk membantu investigator digital forensic di dalam melakukan investigasi jenis serangan cyber pada file syslog.log berbasis web.

\section{Metode Penelitian}

Metode penelitian menggunakan empat tahap di dalam penelitian ini untuk mendapatkan hasil analisis dari file syslog.log. Adapun metode penelitian yang digunakan adalah sebagai berikut:

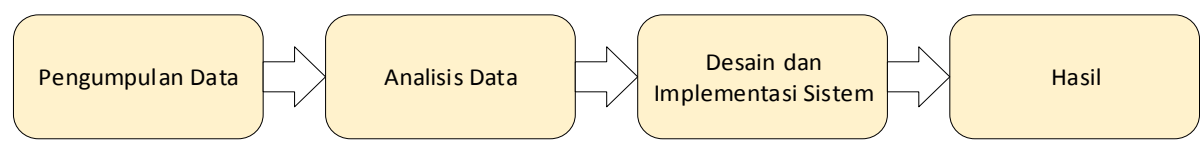

Gambar 1. Metode penelitian.

\subsection{Pengumpulan Data}

Pada tahap pengumpulan data menggunakan jenis data yaitu data sekunder. Data sekunder yang dimaksud adalah data yang didapatkan dari sumber yang sudah ada dalam hal ini adalah file syslog.log pada web server yang mencatat aktivitas serangan pada web server. Sumber data yang digunakan didapatkan dari situs https://www.indonesianbacktrack.or.id/forum/thread-5506.html?highlight=httpd di mana data yang diberikan adalah data file syslog.log dari web server.

\subsection{Analisis Data}

Pada tahap analisis data, file syslog.log tersebut berisi informasi tentang IP Address, aktivitas pengguna, tanggal, waktu akses, serta method yang digunakan dengan format text. Untuk bisa diaplikasikan ke dalam metode K-Means Clustering diperlukan teknik analisis awal untuk mencari hubungan antara frase/kalimat jenis serangan pada file syslog.log serta melakukan pembobotan menjadi data numeric dengan metode TF-IDF. Algoritma K-Means adalah metode partisi terkenal untuk clustering. Metode pengelompokan K-Means, mengelompokkan data berdasarkan kedekatannya satu sama lain sesuai dengan jarak Euclidean. Dibutuhkan $k Y$ sebagai parameter input dan memartisi sekumpulan objek $n$ dari kluster $k Y$. Nilai rata-rata objek diambil sebagai kesamaan parameter untuk membentuk kelompok. Klaster atau pusat rata-rata dibentuk oleh pemilihan acak dari objek $k Y$. Dengan membandingkan sebagian besar kesamaan objek lain yang ditugaskan ke cluster. Untuk setiap vektor data, algoritma ini menghitung jarak antara vektor data dan setiap centroid kluster menggunakan persamaan [4]. Setelah didapatkan informasi dari file syslog.log tahap berikutnya dilakukan tahap desain dan implementasi aplikasi. 


\subsection{Desain dan Implementasi Aplikasi}

Pada tahap desain dan implementasi aplikasi merupakan tahap dibangunnya aplikasi untuk analisis Syslog berbasis web. Pada perancangan aplikasi menggunakan DFD (Data Flow Diagram) serta menggunakan bahasa pemrograman PHP untuk tahap implementasi.

\subsection{Hasil}

Pada tahap hasil, menampilkan informasi dari jenis serangan yang ada di dalam file syslog.log, di mana jenis serangan tersebut diklasifikasikan menggunakan metode K-Means Clustering sehingga informasi jenis serangan bisa diketahui.

\section{Hasil dan Pembahasan}

Untuk mendapatkan informasi jenis serangan cyber pada file syslog.log diperlukan analisis secara manual dan sangat membutuhkan waktu yang lama. Untuk mengatasi hal tersebut, diaplikasikan metode K-Means Clustering untuk mengelompokkan jenis serangan ke dalam aplikasi berbasis web. Di dalam perancangan aplikasi berbasis web menggunakan Data Flow Diagram dan perancangan basis data menggunakan ERD (Entity Realtionship Diagram). Berikut hasil rancangan aplikasinya:

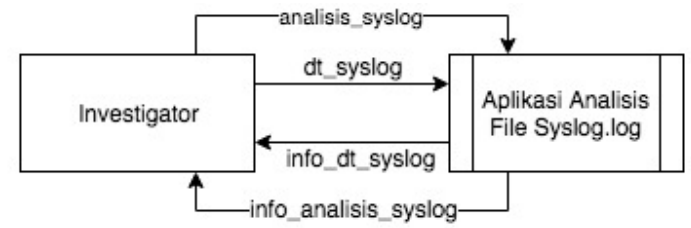

Gambar 2. Diagram konteks aplikasi analisis file Syslog.

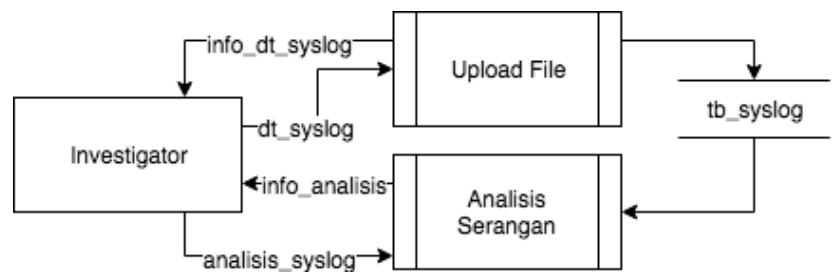

Gambar 3. DFD Level 0.

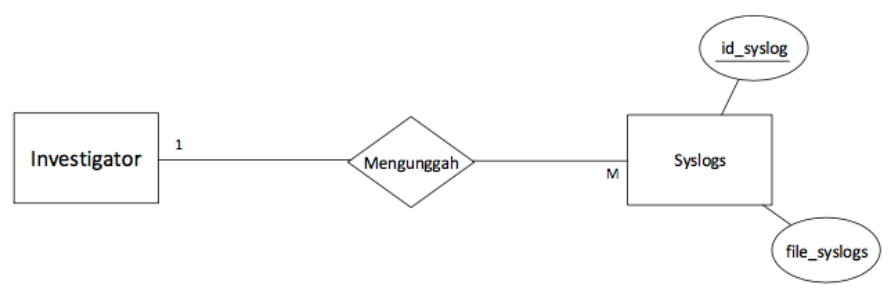

Gambar 4. Konseptual database.

Untuk mengelompokkan jenis serangan pada file syslog.log menggunakan metode K-Means Clustering dan TF-IDF. Tahap pertama mencari frekuensi atau TF (Term Frequency) dari kemunculan suatu serangan pada file syslog.log, yang kedua dilakukan pencarian hubungan ketersediaan istilah dalam hal ini adalah jenis serangan yaitu SQL Injection, XSS Attack, LFI (Local File Inclusion) ketiga jenis serangan tersebut memiliki istilah-istilah atau parameter serangan untuk mencari hubungan yang cocok untuk dibobotkan sehingga menghasilkan data numeric yang digunakan pada proses clustering. Untuk mendapatkan data numeric pada file syslog.log dilakukan konversi menggunakan metode TF-IDF sebagai berikut: 
Tabel 1. Tabel konversi dengan TF-IDF.

\begin{tabular}{|c|c|c|c|}
\hline \multicolumn{4}{|c|}{ Jenis Serangan } \\
\hline No & & SQL Injection & Hasil \\
\hline 1. & select & $\begin{array}{l}\mathrm{IDF}=\log (2 / 1)=0,3010 \\
\mathrm{~W}=1 * 0,3010\end{array}$ & 0,3010 \\
\hline 2. & union & $\begin{array}{l}\mathrm{IDF}=\log (2 / 1)=0,3010 \\
\mathrm{~W}=6 * 0,3010\end{array}$ & 1,8061 \\
\hline No. & & XSS Attack & Hasil \\
\hline 1. & alert & $\begin{array}{l}\mathrm{IDF}=\log (2 / 1)=0,3010 \\
\mathrm{~W}=3 * 0,3010\end{array}$ & 0,9030 \\
\hline 2. & script & $\begin{array}{l}\mathrm{IDF}=\log (2 / 1)=0,3010 \\
\mathrm{~W}=2 * 0,3010\end{array}$ & 0,6020 \\
\hline No. & & $\begin{array}{r}\text { LFI (Local File Inclusion) } \\
\end{array}$ & Hasil \\
\hline 1. & etc & $\begin{array}{l}\mathrm{IDF}=\log (2 / 1)=0,3010 \\
\mathrm{~W}=8 * 0,3010\end{array}$ & 2,4082 \\
\hline 2. & passwd & $\begin{array}{l}\mathrm{IDF}=\log (2 / 1)=0,3010 \\
\mathrm{~W}=9 * 0,3010\end{array}$ & 2,7092 \\
\hline
\end{tabular}

Tabel 2. Hasil konversi dengan TF-IDF.

\begin{tabular}{|c|c|c|c|c|c|c|}
\hline No. & select & etc & passwd & union & script & alert \\
\hline 1 & 0.3010 & 2.4082 & 2.7092 & 1.8061 & 0.6020 & 0.9030 \\
\hline
\end{tabular}

Setelah ditentukan tiap kata dalam bentuk numeric dengan rumus TF-IDF adalah sebagai berikut:

di mana:

$$
D F_{j}=\log \left(D / d f_{j}\right)
$$

D : jumlah dokumen

Df : jumlah dokumen yang mengandung term $\left(t_{j}\right)$

Selanjutnya untuk menghitung bobot $(w)$ digunakan formula sebagai berikut:

di mana:

$$
W_{i j}=T F_{i j} \times I D F_{j}
$$

$W_{i j} \quad$ : adalah bobot term $\left(t_{j}\right)$ terhadap dokumen $\left(d_{i}\right)$

$T F_{i j} \quad$ : jumlah kemunculan term $\left(t_{j}\right)$ dalam dokumen $\left(d_{i}\right)$

Maka proses selanjutnya adalah pengelompokan data menggunakan K-Means. Untuk melakukan pengelompokan data dengan K-Means penulis menentukan terlebih dahulu:

1. Tentukan jumlah cluster.

2. Ambil sembarang data sebanyak jumlah cluster secara acak sebagai pusat klaster (centroid).

3. Hitung jarak antar pusat dengan cluster dengan rumus:

$$
D_{(i, j)}=\sqrt{\left(X_{1 i}-X_{1 j}\right)^{2}+\cdots+\left(X_{k i}-X_{k j}\right)^{2}}
$$

Keterangan:

$D(i, j)=$ Jarak data ke i ke pusat cluster $j$

$X k i=$ Data ke- $i$ pada atribut $k$

$X k j=$ titik pusat ke-j pada atribut $k$

4. Hitung kembali pusat cluster dengan keanggotaan yang baru. Jika pusat cluster tidak berubah maka proses cluster telah selesai. Jika belum ulangi langkah nomor 4 sampai pusat cluster tidak berubah lagi [5].

Untuk mendapatkan informasi jenis serangan pada file syslog.log, dilakukan cluster dengan menggunakan nilai $K=3$, dari 3 cluster tersebut setelah dilakukan perhitungan dengan rumus K-Means maka hasilnya adalah cluster pertama terdapat 12 sampel, cluster kedua 2 sampel, dan cluster ketiga 15 sampel dalam satu dokumen pada file syslog.log di mana cluster pertama adalah SQL Injection, cluster kedua adalah XSS Attack, dan cluster ketiga adalah LFI (Local File Inclusion). Dari hasil perhitungan tersebut dengan K-Means maka data tersebut dapat ditampilkan pada halaman web. Berikut hasil dari proses K-Means Clustering pada Tabel 3. 
Tabel 3. Hasil proses dengan K-Means Clustering.

\begin{tabular}{ccc}
\hline Cluster & Banyaknya Serangan & Kategori \\
\hline Cluster 1 & 12 & SQL Injection \\
\hline Cluster 2 & 2 & XSS Attack \\
\hline Cluster 3 & 15 & LFI (Local File Inclusion) \\
\hline
\end{tabular}

\subsection{Implementasi Aplikasi Analisis File Syslog}

Aplikasi analisis serangan cyber pada file syslog.log menggunakan metode K-Means Clustering untuk klasifikasi serangan cyber berbasis web dibangun menggunakan bahasa pemrograman PHP serta manajemen database menggunakan PHPMyAdmin. Aplikasi ini bertujuan untuk membantu pengguna khususnya investigator di dalam melakukan analisis serangan cyber pada file syslog.log. Berikut hasil implementasi aplikasi berbasis web:

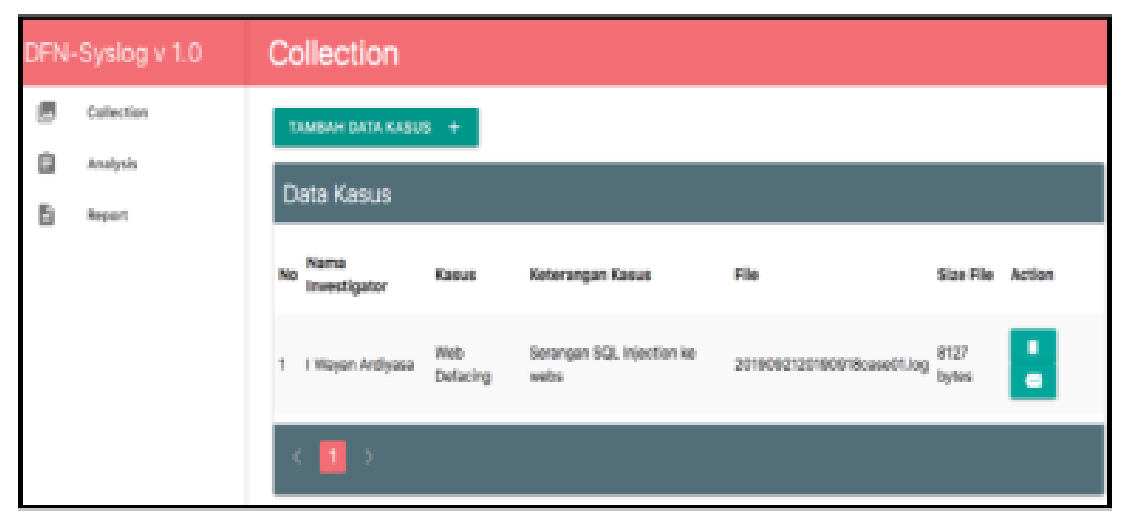

Gambar 5. Antarmuka aplikasi berbasis web.

Pada Gambar 2 merupakan tampilan antarmuka aplikasi yang terdapat 3 menu yaitu collection, analysis, dan report. Pada menu collection merupakan menu untuk isian profile pengguna dan upload file syslog.log. Pada menu analysis merupakan menu untuk melakukan analisis serangan cyber pada file syslog.log untuk mendapatkan informasi jenis serangan dan klasifikasi jenis serangan dan menu report merupakan menu untuk print out hasil klasifikasi serangan cyber.

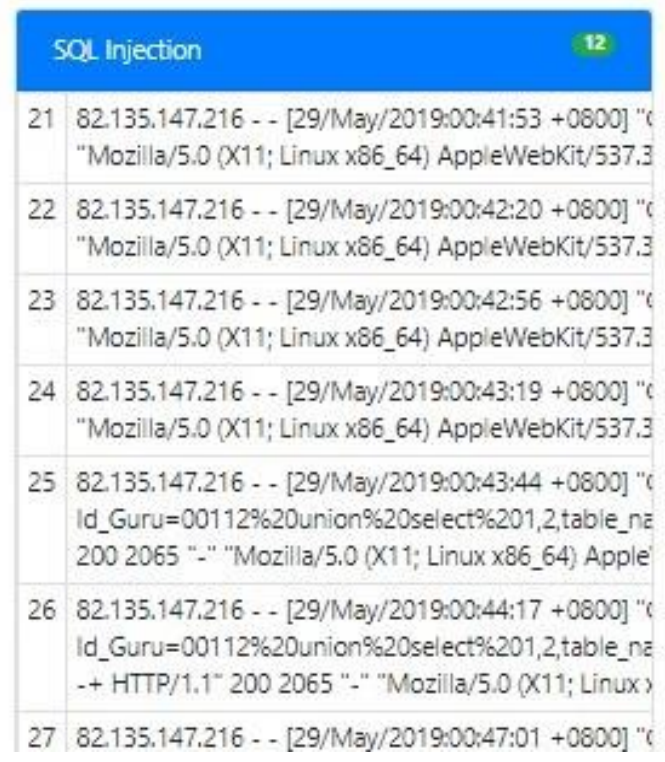

Gambar 6. Analisis SQL injection. 
Pada gambar 3 merupakan hasil pengelompokan jenis serangan cyber SQL Injection. Teknik pengelompokan menggunakan metode K-Means Clustering menggunakan frase select dan union dan didapatkan informasi serangan SQL Injection sebanyak 12 cluster dengan serangan SQL Injection.

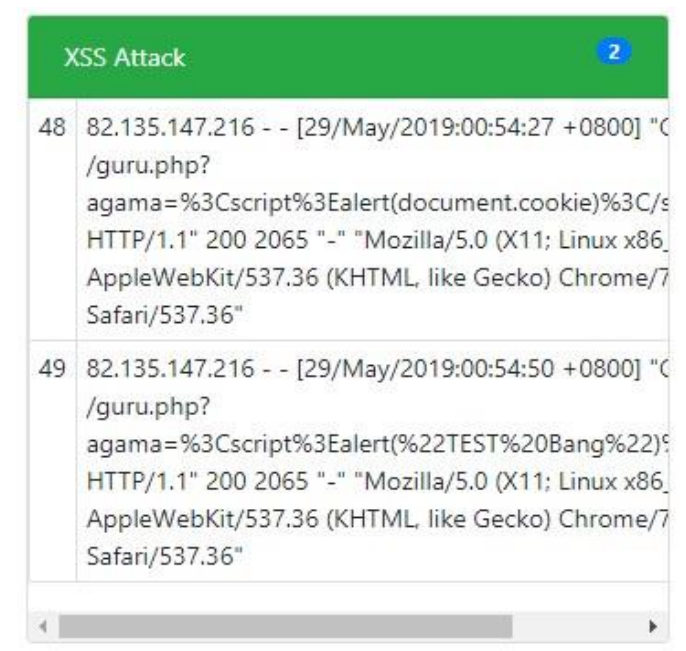

Gambar 7. Analisis XSS attack

Pada Gambar 4 didapatkan hasil clustering jenis serangan cyber XSS Attack. Teknik pengelompokan menggunakan metode K-Means Clustering menggunakan frase alert dan script dan didapatkan informasi serangan XSS Attack sebanyak 2 cluster dengan serangan XSS Attack.

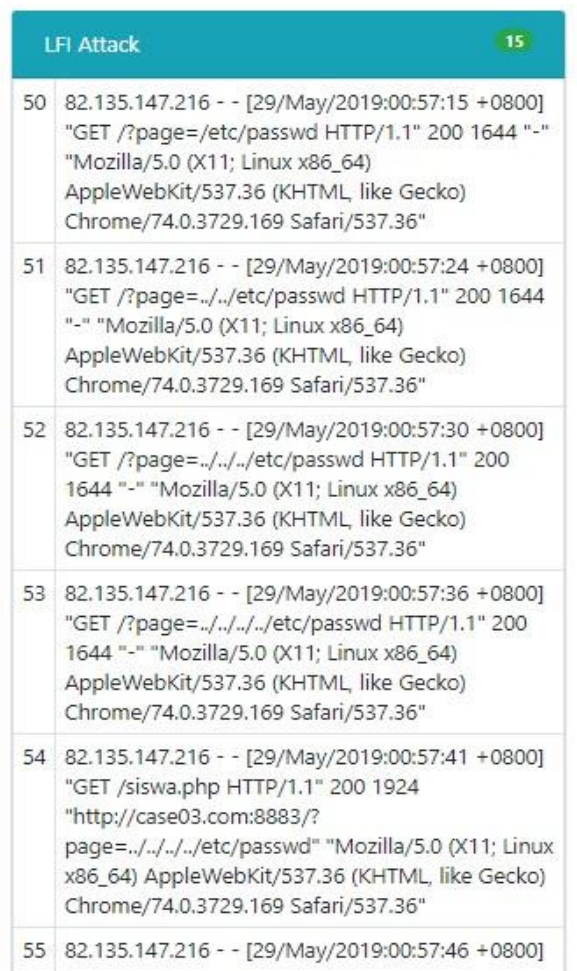

Gambar 8. Analisis LFI (Local File Inclusion).

Pada Gambar 5 didapatkan hasil clustering jenis serangan cyber LFI (Local File Inclusion). Teknik pengelompokan menggunakan metode K-Means Clustering menggunakan frase etc dan passwd dan didapatkan informasi serangan LFI (Local File Inclusion) sebanyak 15 cluster dengan serangan LFI (Local File Inclusion). 
Hasil dari penelitian ini sebagai solusi untuk membantu pengguna khususnya pihak investigator di dalam melakukan analisis barang bukti berupa file syslog.log yang bertujuan untuk mendapatkan informasi serangan cyber dari 3 jenis serangan cyber yaitu SQL Injection, XSS Attack, dan LFI (Local File Inclusion). Aplikasi analisis serangan file syslog.log berbasis web ini, menjadikan tools analisis berbasis grafis user interface menjadi lebih cepat dan user friendly.

\subsection{Pengujian}

Pengujian dengan metode blackbox ini dilakukan dengan cara mencoba fungsionalitas dari sistem tersebut agar sesuai yang diharapkan, berikut hasil dari pengujian menggunakan metode blackbox.

Tabel 4. Hasil pengujian dengan blackbox testing.

\begin{tabular}{|c|c|c|c|}
\hline No. & Skenario Pengujian & Hasil & Kesimpulan \\
\hline 1. & $\begin{array}{l}\text { Mengunggah file Syslog pada kolom upload file, lalu } \\
\text { klik tombol submit }\end{array}$ & $\begin{array}{l}\text { Memunculkan pesan 'File sudah } \\
\text { berhasil di-upload!' }\end{array}$ & Valid \\
\hline 2. & $\begin{array}{l}\text { Mengosongkan kolom upload file, lalu klik tombol } \\
\text { submit }\end{array}$ & Memunculkan pesan 'gagal' & Valid \\
\hline 3. & $\begin{array}{l}\text { Mengunggah file Syslog pada kolom upload file lebih } \\
\text { dari } 2 \mathrm{MB} \text {, lalu klik tombol submit }\end{array}$ & Memunculkan pesan 'File terlalu besar!' & Valid \\
\hline 4. & $\begin{array}{l}\text { Mengunggah file Syslog yang sama pada kolom } \\
\text { upload file, lalu klik tombol submit }\end{array}$ & Memunculkan pesan 'File sudah ada!' & Valid \\
\hline 5. & $\begin{array}{l}\text { Mengunggah file Syslog pada kolom uploadfile } \\
\text { dengan tipe file yang berbeda, lalu klik tombol submit }\end{array}$ & $\begin{array}{l}\text { Memunculkan pesan 'Maaf! Tipe file } \\
\text { tidak sesuai' }\end{array}$ & Valid \\
\hline 6. & $\begin{array}{l}\text { Menghapus salah satu file Syslog, lalu klik ikon } \\
\text { tombol hapus }\end{array}$ & $\begin{array}{l}\text { Memunculkan pesan 'Maaf! Tipe file } \\
\text { tidak sesuai' }\end{array}$ & Valid \\
\hline
\end{tabular}

\section{Kesimpulan}

Telah dihasilkannya aplikasi analisis file syslog.log dengan menggunakan metode K-Means Clustering untuk klasifikasi serangan-serangan cyber dan metode TF-IDF untuk melakukan konversi dari data text menjadi data numeric. Hasil pengujian yang dilakukan dengan menggunakan blackbox testing didapatkan hasil pengujian yang sesuai. Tujuan dari aplikasi ini yaitu untuk membantu pihak pengguna khususnya Investigator Digital Forensic di dalam mencari informasi jenis serangan cyber pada file syslog.log.

\section{Daftar Pustaka}

[1] A. M. Elu, "Rancang Bangun Aplikasi Pendeteksian Vulnerability Structured Query Language (Sql) Injection untuk Keamanan Website," J. Teknol. Inf., vol. VII, no. 1, pp. 111-124, 2013.

[2] N. K. Ariasih and D. P. Hostiadi, "Monitoring Log Service Pada Server Berbasis Web," Semin. Nas. Inform., pp. 190-194, 2014.

[3] Braun, Uri, Y. Zaslavasky, and Y. Teitz, "Syslog Parser,” US11/875,955, 2007.

[4] S. Shah and M. Singh, "Comparison of a time efficient modified k-mean algorithm with K-mean and K-medoid algorithm,” Proc. - Int. Conf. Commun. Syst. Netw. Technol. CSNT 2012, pp. 435-437, 2012.

[5] E. Yulian, "Text Mining dengan K-Means Clustering pada Tema LGBT dalam Arsip Tweet Masyarakat Kota Bandung,” J. Mat. “MANTIK,” vol. 4, no. 1, pp. 53-58, 2018. 